\title{
UTILIZAÇÃO DAS MICROALGAS Thalassiosira weissflogii E Nannochloropsis oculata NO CULTIVO DE Litopenaeus vannamei EM SISTEMAS DE BERÇÁRIOS, SEM RENOVAÇÃO DE ÁGUA.
}

\author{
BELETTINI ${ }^{1}$, F.; DERNER ${ }^{2}$, R.B.; VINATEA ${ }^{2}$, L.A. \\ ${ }^{1}$ Universidade Federal de Santa Catarina, Departamento de Aquicultura, Programa de Pós-Graduação em Aquicultura, CEP 88034-001 \\ Florianópolis, SC, Brasil. E-mail: belettini@lcm.ufsc.br; \\ ${ }^{2}$ Universidade Federal de Santa Catarina, Departamento de Aqüicultura, Programa de Pós-Graduação em Aqüicultura, Laboratório de \\ Camarões Marinhos, CEP 88040-390 Florianópolis, SC, Brasil. E-mail: robertoderner@lcm.ufsc.br, vinatea@mbox1.ufsc.br.
}

\section{RESUMO}

O uso das microalgas, Thalassiosira weissflogii (Diatomácea) e Nannochloropsis oculata (Eustigmatophyceae), em berçários intensivos de Litopenaeus vannamei, sem renovação de água, foi avaliado neste estudo. Três tratamentos (controle, Thalassiosira e Nannochloropsis), foram realizados para observar a influência destas microalgas sobre os parâmetros de qualidade de água, microbiológicos, de qualidade larval e a relação destes com o desempenho dos animais. A densidade de cultivo foi de $65 \mathrm{Pls} / \mathrm{L}$. Além das microalgas, as pós-larvas foram alimentadas com rações comerciais de alto valor protéico (40 a 55\%). As variáveis de qualidade de água: temperatura, oxigênio, $\mathrm{pH}$, salinidade, alcalinidade, concentração de nitrito e nitrato, mantiveram-se dentro dos valores normais para a espécie Litopenaeus vannamei. Níveis elevados de amônia e fosfato foram observados, mas sem influenciar na sobrevivência. A disponibilidade de nutrientes favoreceu o aumento de bactérias do gênero Vibrio. A sobrevivência, nível de proteína bruta nas pós-larvas, resposta ao teste de stress, tamanho e qualidade larval das pós-larvas, não apresentaram diferenças significativas. Diferenças foram encontradas no ganho de peso. O tratamento com a microalga Thalassiosira weissflogii apresentou os melhores valores médios de peso seco e por consequência, maior ganho de peso e biomassa final foram observados.

PALAVRAS CHAVE: cultivo em berçários, Litopenaeus vannamei, qualidade de água, microalgas

\section{ABSTRACT}

Use of microalgae Thalassiosira weissflogii and Nannochloropsis oculata in nurseries of Litopenaeus vannamei with zero water exchange

The use of microalgae, Thalassiosira weissflogii (Diatom) and Nannochloropsis oculata (Eustigmatophyceae) in intensive nurseries with Litopenaeus vannamei, with zero water exchange, was evaluated in this study. Three treatments (control, Thalassiosira and Nannochloropsis) were conducted to observe the influence of microalgae on the parameters of water quality, microbiological, quality of larvae and their relationship with animal performance. The stocking density was $65 \mathrm{Pls} / \mathrm{L}$. In addition to the microalgae, the post-larvae were fed with commercial diets high in protein $(40-55 \%)$. The variables of water quality: temperature, oxygen, $\mathrm{pH}$, salinity, alkalinity, concentrations of nitrite and nitrate, remained within the normal range for the species Litopenaeus vannamei. High levels of ammonia and phosphate were observed, but no influence on survival. The availability of nutrients favored the increase of pathogenic bacteria of the genus Vibrio. Survival, crude protein level in postlarvae, response to stress test, larval size and quality of post-larvae showed no significant differences. Differences were found in weight gain. Treatment with the microalgae Thalassiosira weissflogii exhibited the highest values of dry weight and consequently, greater weight gain and final biomass were observed.

KEYWORDS: intensive nurseries, Litopenaeus vannamei, water quality, microalgae

\section{INTRODUÇÃO}

Nos estágios iniciais de desenvolvimento o aporte de nutrientes às larvas de camarão marinho é feito por meio de microalgas, que na sua maioria são ricas em ácidos graxos poliinsaturados (PUFAs), principalmente docosaexaenóico (DHA) e eicosapentaenóico (EPA), sendo as Diatomáceas as mais utilizadas devido à presença destes nutrientes essenciais à sobrevivência e crescimento dos camarões (DANTAS et al. 2007).

Dentre as diatomáceas, as microalgas do gênero Chaetoceros sp. são as mais utilizadas devido a sua maior facilidade de produção em larga escala. No entanto, o uso da Thalassiosira sp. e o seu desempenho como alimento para diferentes espécies de camarões marinhos, utilizada de forma isolada ou em combinações com outras espécies de microalgas, foi reportado por diferentes autores mencionados por
Derner (2006), atribuindo vantagens como: maior velocidade de metamorfose, maior crescimento e maior sobrevivência das larvas, isto provavelmente relacionado à sua composição bioquímica.

Estudos realizados mostram que as microalgas do gênero Nannochloropsis sp. são uma fonte potencial do ácido graxo eicosapentaenóico (SUKENIK 1999), aumentando o interesse dos pesquisadores no desenvolvimento de pesquisas com esta microalga no que diz respeito à possibilidade do aumento do nível de EPA. Hu \& Gao (2006) demonstraram que a elevação da concentração de $\mathrm{CO}_{2}$, temperatura baixa, baixa salinidade, níveis moderados de fosfato e excessivos de nitrato, são fatores favoráveis para o aumento do rendimento do EPA em Nannochloropsis sp. 
O uso de tanques berçários para adaptação ou aclimatação de pós-larvas de camarão marinho antes da engorda é uma alternativa que demanda certo nível de investimento e adaptações nos laboratórios de produção e nas fazendas de cultivo, mas que trazem benefícios, tais como, melhora da taxa de sobrevivência durante a engorda, uniformidade de tamanho durante as despescas, melhor utilização da infra-estrutura, aumento do número de despescas por ano e redução da perda de alimentos através da produção de indivíduos mais robustos com melhor desempenho zootécnico durante a engorda (SAMOCHA \& LAWRENCE 1992; BARBIERI e OSTRENSKY 2002).

Um aspecto importante que precisa atenção no cultivo em berçários intensivos sem renovação é a qualidade de água (EBELING et al. 2006). A necessidade da utilização de rações de alto valor proteico, como complemento alimentar, favorece a elevação dos níveis de amônia na água. Concentrações letais ou sub-letais de amônia $\left(\mathrm{NH}_{3}\right)$ podem causar mortalidades em larviculturas de Litopenaeus vannamei (BARAJAS et al. 2006). Vinatea (2004) refere-se à amônia como o principal produto da excreção dos organismos aquáticos e o seu efeito varia desde alterações no mecanismo de excreção ao aumento da suscetibilidade às doenças.

A amônia residual presente nos cultivos pode ser removida da água por via biológica através da absorção por microalgas, bactérias autotróficas ou heterotróficas (EBELING et al. 2006), ou ainda, pode ser reduzido para níveis aceitáveis através do

\section{MATERIAIS E MÉTODOS}

Este trabalho avaliou o efeito das microalgas $T$. weissflogii e $N$. oculata em berçários intensivos com pós-larvas (PLs) do camarão marinho $L$. vannamei, sem renovação de água, entre os estágios de póslarva 12 a 20, durante nove dias, em 12 unidades experimentais, no Setor de Berçários do Laboratório de Camarões Marinhos (LCM-UFSC).

Como unidades experimentais foram utilizadas caixas de polipropileno pretas, com $47 \mathrm{~cm}$ de profundidade e volume total de $200 \mathrm{~L}$, com aeração e aquecimento constante. As caixas foram colocadas em banho-maria dentro de um tanque circular de fibra processo de renovação da água, havendo a necessidade da reposição constante das microalgas e como consequência, aumento dos custos de produção.

O aparecimento de doenças nos cultivos de camarões marinhos pode não ser resultado apenas da intensificação das densidades de produção, mas também da presença de distúrbios ecológicos, alimentares ou da poluição (KAUTSKY et al. 2000). O acúmulo de matéria orgânica pode ser ocasionado pela alta densidade de microalgas ou pela excreção das larvas (THOMPSON et al. 2002). O excesso de matéria orgânica leva ao acúmulo de nutrientes como a amônia (MADIGAN et al. 2004), favorecendo a multiplicação de bactérias oportunistas, como as do gênero Vibrio.

De acordo com Igarashi et al. (1996), a quantificação da contribuição da microalga Nannochloropsis no processo de purificação da água é difícil, no entanto, pode-se sugerir que a sua presença durante o cultivo aumentou a sobrevivência de pós-larvas de Penaeus japonicus, cultivados na mesma água por um longo período, podendo eliminar e controlar o desenvolvimento de bactérias na água de cultivo, melhorando assim a sobrevivência dos indivíduos.

O objetivo deste estudo é avaliar o efeito das microalgas Thalassiosira weissflogii e Nannochloropsis oculata em berçários intensivos de Litopenaeus vannamei sobre os parâmetros microbiológicos, de qualidade da água e sobre o desempenho zootécnico dos animais.

de vidro com 50.000 L de capacidade, em estufa coberta para auxiliar na manutenção da temperatura. As unidades experimentais foram abastecidas com $190 \mathrm{~L}$ de água, primeiramente clorada com 2,5 ppm de hipoclorito de cálcio a $65 \%$ e neutralizada com tiossulfato de sódio (grau técnico) na proporção de 1 grama de tiossulfato para cada 1 ppm de cloro residual.

O delineamento experimental foi definido por três tratamentos (Controle, Nannochloropsis oculata e Thalassiosira weissflogii), com quatro repetições cada e densidade de estocagem de 65 pós-larvas/L, 
padrão nos berçários do LCM, totalizando 12.350 pós-larvas em cada unidade experimental.

As pós-larvas de camarão marinho $L$. vannamei utilizadas no experimento foram transferidas no estádio de PL 12, do Setor de Larvicultura do LCM, para cada unidade experimental. Uma amostra de 245 larvas foi usada para determinar o peso seco médio inicial e o valor protéico. Depois de definido o peso úmido em balança eletrônica $(0,01 \mathrm{~g})$, as póslarvas foram colocadas em uma estufa a $45{ }^{\circ} \mathrm{C}$ até estabilizar o peso; transferidas para o dessecador por 15 minutos e verificado o peso seco médio inicial, que foi de $0,4245 \mathrm{mg} / \mathrm{PL}$.

No dia anterior ao povoamento foram colocadas as culturas puras das microalgas $N$. oculata e T. weissflogii, provenientes do Setor de Microalgas, cultivadas em meio F/2 de Guillard (1975) modificado, segundo Derner (2006), mantendo-se a transparência inicial em $30 \mathrm{~cm}$, comumente utilizado nesta fase de cultivo no LCM. Nas unidades controle não foram utilizadas microalgas. A densidade celular inicial das microalgas foi determinada em microscópio óptico, com o auxílio de um hemocitômetro (câmara de Neubauer) e foi de $256,2 \times 10^{4} \mathrm{cel} . / \mathrm{ml}$ no tratamento com a $N$. oculata e $10,5 \times 10^{4} \mathrm{cel} . / \mathrm{ml}$ no tratamento com a $T$. weissflogii. Durante o experimento as densidades de microalgas foram determinadas diariamente pela manhã.

Uma amostra de $200 \mathrm{ml}$ foi coletada de cada uma das espécies de microalgas para determinar a biomassa inicial. Verificada a densidade celular inicial de cada uma das amostras, estas foram diluídas a $1 / 2$ e $1 / 4$ respectivamente. Paralelo a isto, seis micro filtros de fibra de vidro (GF-1; $47 \mathrm{~mm}$ de diâmetro) foram identificados, colocados em estufa a $60{ }^{\circ} \mathrm{C}$ por 1 hora, deixados em dessecador por 15 minutos $\mathrm{e}$ posteriormente pesados em balança eletrônica $(0,0001 \mathrm{~g})$. De cada diluição foram filtrados $10 \mathrm{ml}$, em duplicata. Os filtros foram novamente colocados em estufa a $60{ }^{\circ} \mathrm{C}$ por 12 horas, deixados em dessecador por 15 minutos e pesados. A diferença de peso obtida refere-se à biomassa de microalgas, relativa à densidade celular das duas espécies de microalgas no início do experimento.

A concentração de clorofila-a em $\mathrm{mg} / \mathrm{m}^{3}$ foi determinada por espectrofotometria seguindo a metodologia 10200 H (APHA 1995). As análises foram realizadas no primeiro, quinto e nono dia do experimento.

Além das microalgas, as pós-larvas foram alimentadas com rações comerciais micro particuladas $(40 \%$ a $50 \%$ PB). Diariamente foram ofertadas 10 alimentações onde a composição das dietas variou em função do tamanho da partícula e idade das pós-larvas (Tabela 1). À medida que as pós-larvas evoluíam em estágio larval, a quantidade de alimento inicial (50 g/milhão de pós-larvas) foi aumentada em $25 \%$ no terceiro e sexto dias, independente da sobrevivência existente.

TABELA 1 - Composição das dietas, tamanho das particuladas, horários de alimentação e tipo de dieta fornecida para as pós-larvas de $L$. vannamei durante o experimento em berçários intensivos sem renovação de água.

\begin{tabular}{c|c|c|c|c|c|c|c|c|c|c}
\hline Dietas & \multicolumn{7}{c}{ Composição } \\
\hline A & \multicolumn{7}{c}{$50 \% \mathrm{RC}^{*} 200-300 \mu \mathrm{m}+50 \%$ RC $300-500 \mu \mathrm{m}$} \\
\hline B & $50 \%$ RC $300-500 \mu \mathrm{m}+50 \%$ RC $500 \mu \mathrm{m}$ \\
\hline C & \multicolumn{7}{c}{$100 \%$ RC $300-500 \mu \mathrm{m}$} \\
\hline D $^{*}$ & \multicolumn{10}{c}{$100 \%$ RC } \\
\hline Horários & $01: 00$ & $06: 00$ & $08: 00$ & $10: 00$ & $12: 00$ & $14: 00$ & $16: 00$ & $18: 00$ & $21: 00$ & $24: 00$ \\
\hline Dieta & A/B & D & C & A/B & A/B & D & C & A/B & C & A/B \\
\hline
\end{tabular}

$\mathrm{RC}^{*}$ : ração comercial

$D^{*}$ : ração comercial moída e passada em malha de $500 \mu \mathrm{m}$. 
A avaliação da qualidade das pós-larvas foi realizada segundo Knoll et al. (2007). No final do experimento, 25 pós-larvas de cada unidade experimental foram observadas para verificar critérios de relevância fisiológica, comportamental (atividade natatória), nutricional e sanitária. Também no final do estudo, 100 pós-larvas de cada unidade experimental foram submetidas ao teste de stress salino para verificar a sua resistência. As larvas foram retiradas aleatoriamente da água salgada com auxílio de uma jarra plástica de 1 litro, retidas em malha de $500 \mu$ e colocadas diretamente em água doce por 30 minutos, retornando para a água salgada por igual período de tempo. Após isso foi verificada a sobrevivência em cada uma das unidades experimentais.

Os índices de desempenho zootécnico das pós-larvas foram verificados através do peso seco médio, da porcentagem de sobrevivência final (\%S (sobrevivência) $=($ pop. inicial - pop. final) $\times 100) ;$ do ganho de peso $\left(\boldsymbol{G P}\right.$ (ganho peso) $_{\text {e }} \boldsymbol{P S 2}$ (peso seco final) PS1 (peso seco inicial)); da biomassa total produzida (BTP (biomassa total produzida) $=G P$ (ganho peso) $x$ população final); do coeficiente de variação, relacionado ao tamanho das pós-larvas $\left(\boldsymbol{C} \boldsymbol{V}_{\text {(coef. variação) }}=(\right.$ desvio padrão / comprimento médio) $x$ 100) e pelo percentual de crescimento diário em peso seco (TEC (\%cresc. dia $\left.{ }^{-1}\right)=100 \times\left(\right.$ In (log. natural) $P F_{(\text {peso seco final) }}-$ In PI (peso seco inicial) $/ \boldsymbol{T}_{\text {(tempo em dias). }}$ O valor de proteína bruta inicial das pós-larvas 12 e o valor final existente em cada tratamento foi determinado através da metodologia descrita por AOAC (2005).

Os parâmetros de qualidade de água: temperatura $\left(\mathrm{T}^{\circ} \mathrm{C}\right)$, oxigênio dissolvido (OD), $\mathrm{pH}$ e transparência foram acompanhados diariamente pela manhã com o auxílio de um oxímetro YSI (Yellow Springs Instruments) modelo F-1055 (precisão de $0,01 \mathrm{mg} \cdot \mathrm{L}^{-1}$ ), um eletrodo de $\mathrm{pH}$ Goulton (precisão de 0,01) e um disco de Secchi, respectivamente. Amostras de água foram coletadas das unidades experimentais para determinar a alcalinidade, salinidade, nutrientes inorgânicos dissolvidos e a produtividade primária, no início, meio e término do experimento. A análise destes parâmetros foi feita no
Laboratório de Qualidade de Água do LCM.

Para determinação da salinidade foi utilizado um refratômetro ótico, marca Biobrix. A alcalinidade total foi medida segundo o procedimento de análise 004-ALFAKIT, com reagentes previamente preparados e fornecidos pela empresa Alfa Tecnoquímica.

As amostras de água coletadas foram filtradas em membranas de porosidade controlada $(0,45$ micras) para a eliminação do material particulado. A fração filtrada foi então dividida em alíquotas para a determinação colorimétrica do nitrato, nitrito, nitrogênio amoniacal e fosfato. O procedimento metodológico foi baseado nas propostas de APHA (1995), utilizando-se um fotocolorímetro AT2K da ALFAKIT com kits de reagentes preparados $e$ fornecidos pela empresa Alfa Tecnoquímica.

A avaliação dos sólidos suspensos foi feita através do uso de Cones Imhoff por medição volumétrica do depósito formado depois de 15 minutos de decantação.

A determinação do crescimento bacteriano total e de vibrionáceas foi realizada no Setor de Microbiologia do LCM. Amostras de água e de larvas foram coletadas no início e no término do estudo e semeadas por meio de diluições sucessivas em meios para bactérias totais marinhas (TSA) e vibrionáceas (Agar Tiossulfato Citrato Bile Score, TCBS), segundo Vieira et al. (2007).

O desempenho das duas espécies de microalgas em relação aos parâmetros de qualidade da água, microbiológicos e índices zootécnicos das pós-larvas do camarão marinho L. vannamei, foram analisados estatisticamente (Statistica $7.0^{\circledR}$ ). Primeiramente os dados foram avaliados quanto à homocedasticidade das variâncias e distribuição normal. Após isto, foi realizada a análise de variância unifatorial (One-way ANOVA) e para as diferenças significativas verificadas foi utilizado o teste de separação de médias de TUKEY com índice de significância de $P<0,05$. A relação entre a densidade e a biomassa das microalgas foi avaliada usando análise de regressão. 


\section{RESULTADOS E DISCUSSÃO}

Através da análise de regressão $\left(R^{2}=0,9592\right.$ para a $T$. weissflogii e 0,7414 para a $N$. oculata), foi possível determinar que à medida que existiu um aumento na densidade celular, este, representou também um aumento na biomassa das espécies de microalgas utilizadas neste estudo. No entanto, mesmo com uma densidade celular média maior durante o experimento, os menores valores de biomassa e produção de clorofila-a encontrados no cultivo com $N$. oculata (Tabela 2), estão relacionados ao tamanho menor da célula nesta espécie, de acordo com Pereira \& Soares-Gomes (2002).
Segundo estes mesmos autores, a diminuição da quantidade de clorofila- $a$, observada na fase final do cultivo, é um reflexo do estado fisiológico das células, ainda que, para a $N$. oculata, a densidade celular média diária estivesse aumentando (Figura 1). Este estado fisiológico ruim das microalgas pode indicar que a cultura atingiu, dentro da sua curva de crescimento, a fase de morte da cultura (DERNER 2006), aumentando a quantidade de protozoários e formação de grumos de células mortas, bactérias e material orgânico, refletindo no aumento da formação de sólidos sedimentáveis, sobretudo no tratamento com T. weissflogii (Figura 2).

TABELA 2 - Valores médios e desvio padrão da densidade celular, clorofila a e biomassa das microalgas $N$. oculata e $T$. weissflogii, utilizadas no cultivo de pós-larvas de L. vannamei em berçários intensivos sem renovação de água.

\begin{tabular}{l|rrr}
\hline Variáveis & \multicolumn{2}{|l}{ Tratamentos } & \\
& Controle & N.oculata & \multicolumn{1}{c}{ T. weissflogii } \\
\hline Densidade celular $\left(\times 10^{4} \mathrm{cel} / \mathrm{ml}\right)$ & $0,1( \pm 0,3)^{\mathrm{b} *}$ & $870,1( \pm 366,4)^{\mathrm{a}}$ & $17,8( \pm 4,3)^{\mathrm{b}}$ \\
Clorofila- $a\left(\mathrm{mg} / \mathrm{m}^{3}\right)$ & $7 \times 10^{-4}\left( \pm 8 \times 10^{-4}\right)^{\mathrm{c} *}$ & $0,014( \pm 0,008)^{\mathrm{b}}$ & $0,080( \pm 0,030)^{\mathrm{a}}$ \\
Biomassa $(\mathrm{mg} / \mathrm{L})$ & $0,07( \pm 0,09)^{\mathrm{c} *}$ & $0,46( \pm 0,11)^{\mathrm{b}}$ & $1,11( \pm 0,17)^{\mathrm{a}}$ \\
\hline
\end{tabular}

Letras sobrescritas diferentes indicam diferença estatística significativa, TUKEY $(p<0,05)$.

*Contaminação por N.oculata na fase final do experimento 


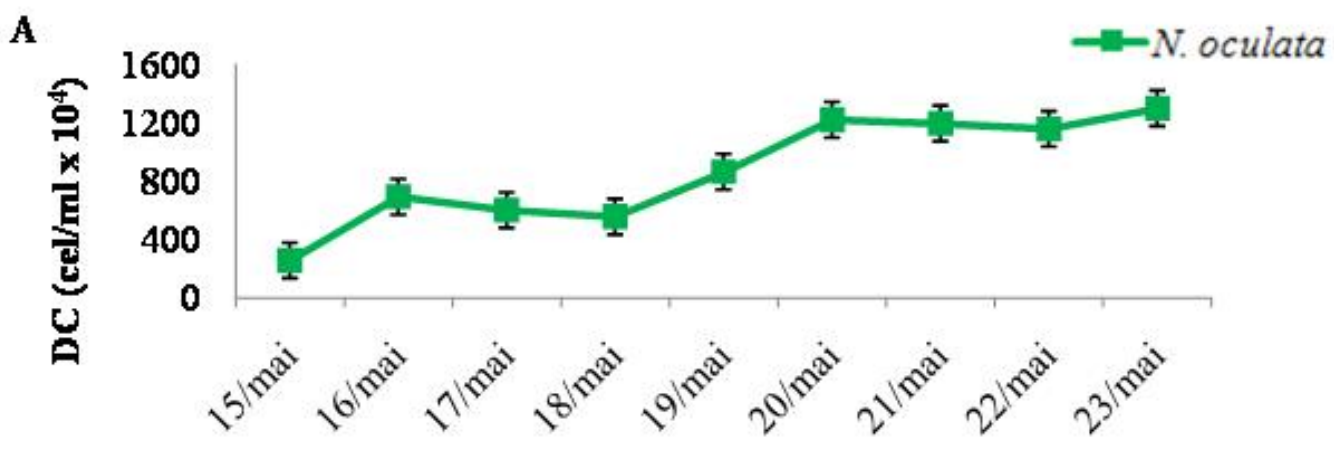

Dias de cultivo

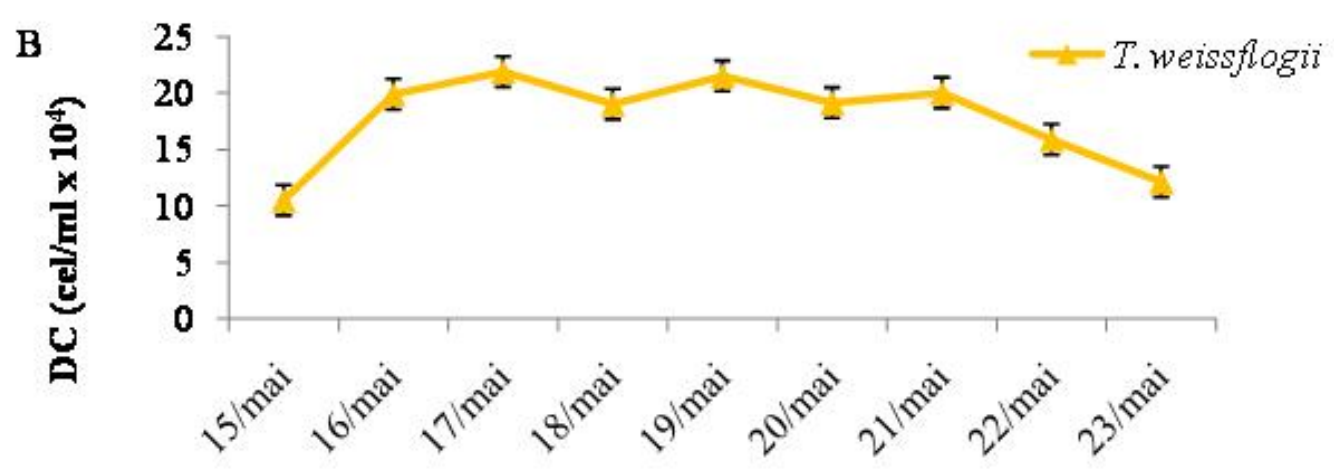

Dias de cultivo

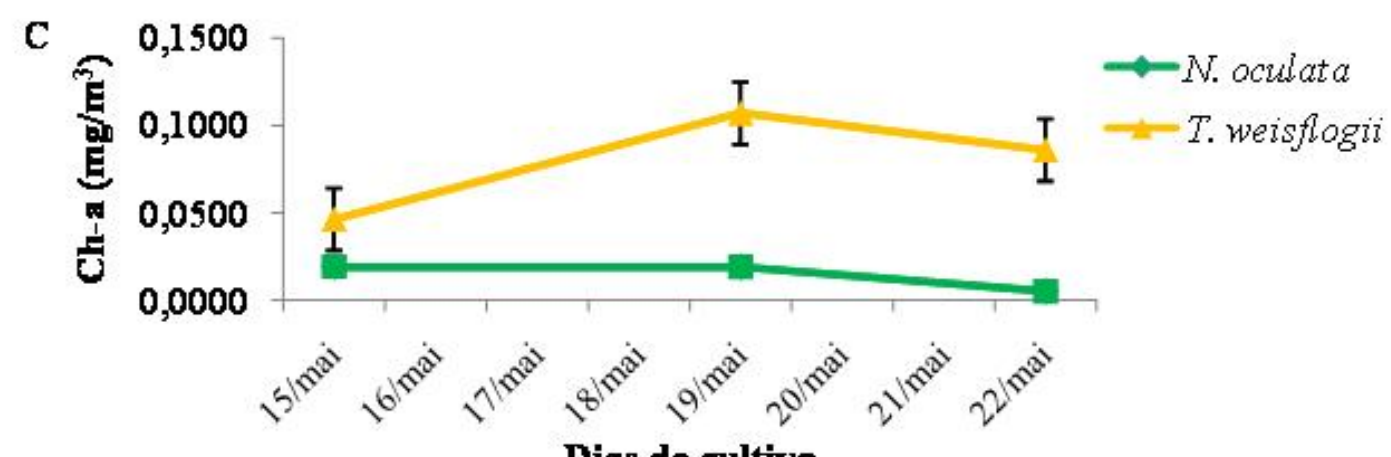

Dias de cultivo

FIGURA 1 - Curvas de crescimento (A e B), concentração de clorofila-a (C) das microalgas Nannochloropsis oculata e Thalassiosira weissflogii, durante o cultivo de pós-larvas de L. vannamei em berçários intensivos sem renovação de água. 


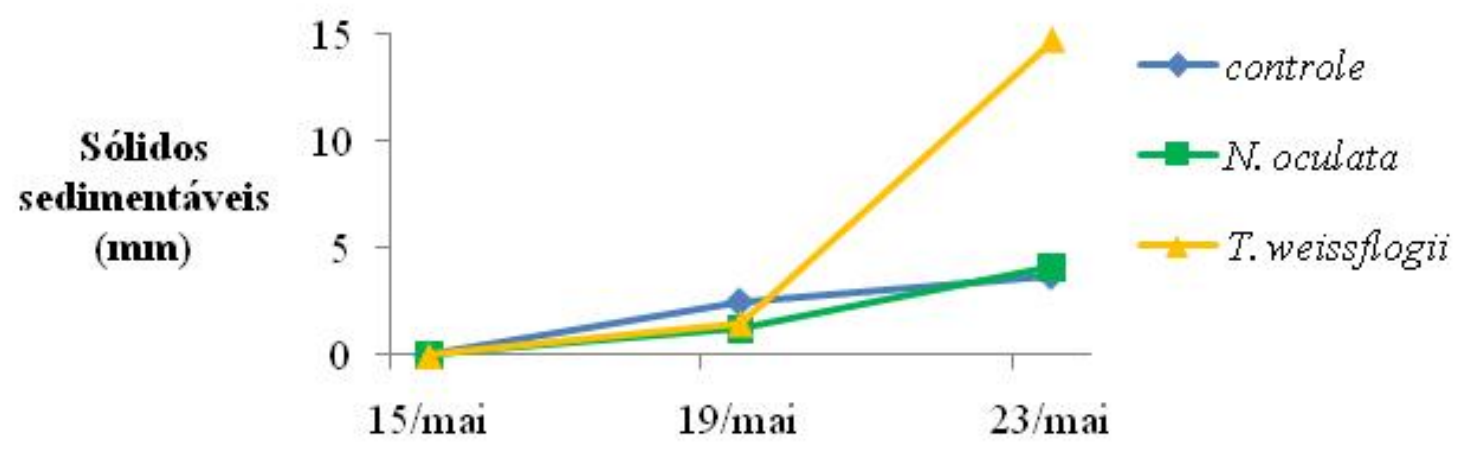

Dias de cultivo

FIGURA 2 - Médias de sólidos sedimentáveis, em Cones Imhoff, durante o cultivo de L. vannamei em berçários intensivos sem renovação de água, dos tratamentos controle, N. oculata e T. weissflogii.

Além de influenciar na transparência da água, o aporte de material orgânico, restos de alimento e fezes favorecem o aparecimento de bactérias oportunistas como o Vibrio sp. (MOURIÑO et al. 2008), devido ao acúmulo de nutrientes como amônia, nitrato e fosfato (MADIGAN et al. 2004), podendo assim causar infecções nas pós-larvas. Apesar do aumento do número de vibrionáceas observado em todos os tratamentos, seja na água ou nas pós-larvas durante o estudo, isto não foi suficiente para infectar e alterar a qualidade das póslarvas durante o cultivo (Tabela 3).

TABELA 3 - Número médio e desvio padrão do número de bactérias totais (TSA) e vibrionáceas (TCBS), da água e das pós-larvas, no inicio e ao final do cultivo de pós-larvas de Litopenaeus vannamei em berçários intensivos sem renovação de água.

\begin{tabular}{l|rlcc}
\hline Varióveis & Inicial & Controle-final & N. oculata-final & T. weissflogii-final \\
\hline TCBS água: $\log _{10}$ (UFC/ml) & $2,7( \pm 0,4)$ & $7,3( \pm 0,5)$ & $7,4( \pm 0,5)$ & $8,1( \pm 0,1)$ \\
TSA água: $\log _{10}$ (UFC/ml) & $5,9( \pm 0,1)$ & $2,8( \pm 1,3)$ & $3,0( \pm 0,5)$ & $3,1( \pm 1,0)$ \\
TCBS pós-larva: $\log _{10}$ (UFC/g) & $2,3( \pm 0,3)$ & $5,7( \pm 0,6)$ & $5,3( \pm 1,0)$ & $5,2( \pm 0,4)$ \\
TSA pós-larva: $\log _{10}$ (UFC/g) & $4,7( \pm 0,1)$ & $1,2( \pm 1,3)$ & $1,0( \pm 1,3)$ & $0,9( \pm 1,6)$ \\
\hline
\end{tabular}

Valores transformados em log $(x+1)$ anteriormente a análise.

Letras sobrescritas diferentes indicam diferença estatística significativa, TUKEY $(p<0,05)$.

Em relação às variáveis de qualidade de água (Tabela 4), as médias de $\mathrm{pH}$, oxigênio dissolvido e alcalinidade, mantiveram-se dentro da faixa ideal para o cultivo do camarão marinho Litopenaeus vannamei, segundo Boyd (1998) e Sociedade Latino-Americana de Aquacultura (SLA) (2009). A salinidade média obtida neste estudo esteve acima desta faixa ideal (BOYD 1998). No entanto, este mesmo autor coloca que esta espécie pode ser cultivada com êxito em salinidades maiores ou menores do que as ideais. 
TABELA 4 - Valores médios e desvio padrão dos parâmetros físico-químicos da qualidade da água durante 0 cultivo de pós-larvas de $L$. vannamei em berçários intensivos sem renovação de água com as microalgas $N$. oculata e T. weissflogii.

\begin{tabular}{l|llc}
\hline \multicolumn{1}{c|}{ Variáveis } & \multicolumn{3}{|c}{ Tratamentos } \\
& Controle & N. oculata & T. weissflogii \\
\hline Salinidade $(\%)$ & $38,60( \pm 2,70)^{\mathrm{a}}$ & $38,72( \pm 2,60)^{\mathrm{a}}$ & $38,60( \pm 2,47)^{\mathrm{a}}$ \\
Temperatura $\left({ }^{\circ} \mathrm{C}\right)$ & $25,82( \pm 2,35)^{\mathrm{a}}$ & $25,79( \pm 2,29)^{\mathrm{a}}$ & $25,80( \pm 2,33)^{\mathrm{a}}$ \\
$\mathrm{pH}$ & $7,89( \pm 0,19)^{\mathrm{bc}}$ & $7,96( \pm 0,13)^{\mathrm{ab}}$ & $7,95( \pm 0,14)^{\mathrm{a}}$ \\
Oxigênio $\left(\mathrm{mg} / \mathrm{L} \mathrm{O}_{2}\right)$ & $6,73( \pm 0,69)^{\mathrm{a}}$ & $6,90( \pm 0,68)^{\mathrm{a}}$ & $6,93( \pm 0,60)^{\mathrm{a}}$ \\
Transparência $(\mathrm{cm})$ & $66,6( \pm 38,1)^{\mathrm{b}}$ & $18,2( \pm 7,7)^{\mathrm{a}}$ & $18,2( \pm 7,1)^{\mathrm{a}}$ \\
Alcalinidade Total $\left(\mathrm{ppm} \mathrm{CaCO}_{3}\right)^{*}$ & $130( \pm 17,7)^{\mathrm{b}}$ & $139( \pm 35,4)^{\mathrm{ab}}$ & $140( \pm 40,1)^{\mathrm{a}}$ \\
Amônia $\left(\mathrm{mg} / \mathrm{L} \mathrm{N}-\mathrm{NH}_{4}\right)^{*}$ & $3,43( \pm 3,12)^{\mathrm{b}}$ & $1,98( \pm 2,48)^{\mathrm{a}}$ & $1,88( \pm 2,53)^{\mathrm{a}}$ \\
Nitrato $\left(\mathrm{mg} / \mathrm{L} \mathrm{N}-\mathrm{NO}_{3}\right)^{*}$ & $0,64( \pm 0,67)^{\mathrm{b}}$ & $1,65( \pm 0,89)^{\mathrm{a}}$ & $1,16( \pm 0,72)^{\mathrm{ab}}$ \\
Nitrito $\left(\mathrm{mg} / \mathrm{L} \mathrm{N}-\mathrm{NO}_{2}\right)^{*}$ & $0,10( \pm 0,17)^{\mathrm{b}}$ & $0,26( \pm 0,10)^{\mathrm{a}}$ & $0,34( \pm 0,16)^{\mathrm{a}}$ \\
Fosfato $(\mathrm{mg} / \mathrm{L} \mathrm{P-PO})^{*}$ & $1,45( \pm 0,92)^{\mathrm{c}}$ & $0,95( \pm 0,63)^{\mathrm{b}}$ & $0,40( \pm 0,33)^{\mathrm{a}}$ \\
\hline
\end{tabular}

* Dados monitorados nos dias um, cinco e nove do experimento.

Letras sobrescritas diferentes indicam diferença estatística significativa, TUKEY $(p<0,05)$.

A temperatura é um fator importante no cultivo, pois pode influenciar diretamente o metabolismo dos animais, interferindo, por exemplo, no consumo de alimento e no ciclo de muda, refletindo assim no crescimento dos camarões. As médias de temperatura entre os tratamentos ficaram abaixo do intervalo considerado ideal por Boyd (1998), que é de 28 a $30{ }^{\circ} \mathrm{C}$, porém não interferiram no desenvolvimento das pós-larvas.

Os níveis de amônia foram bastante elevados, sobretudo no final do experimento. O efeito deste nível mais alto deveria ser sentido, segundo Vinatea (2004), no crescimento dos camarões. A diferença significativa verificada no tratamento sem a presença das microalgas corrobora a afirmação deste autor, em relação ao comprimento das pós-larvas, onde estas atingiram um comprimento médio menor quando comparado aos tratamentos com a presença das microalgas. Em relação ao crescimento em peso, esta afirmação é mais aceitável no tratamento com a presença de $N$. oculata, pois no tratamento com a microalga $T$. weissflogii, mesmo em menor concentração, mas ainda acima dos valores máximos reportados por Boyd (1998) e SLA (2009), 1,0 $\mathrm{mgL}^{-1} \mathrm{e}$ $0,20 \mathrm{mgL}^{-1}$ respectivamente, houve um aumento considerável no peso seco médio das pós-larvas. O efeito dos níveis elevados de amônia sobre a sobrevivência das pós-larvas não foi observado neste estudo, uma vez que o valor calculado para amônia tóxica ao final do experimento, levando-se em consideração a média de temperatura e $\mathrm{pH}$, no tratamento controle, foi de $0,20 \mathrm{mgL}^{-1}$, dentro, portanto do nível de segurança para a espécie. A quantidade de alimento ofertada e a densidade de cultivo favoreceram o aumento da concentração de amônia neste tratamento. Nos tratamentos com as microalgas estes valores ficaram mais baixos, 0,14 $\mathrm{mgL}^{-1}$, o que mostra que a presença das microalgas diminui a concentração deste nutriente.

Os níveis de nitrito observados estão dentro da faixa tolerada para o L. vannamei, segundo Boyd (1998) e SLA (2009). As maiores concentrações verificadas no final ocorreram devido ao processo de nitrificação, onde a amônia é transformada a nitrito pela ação de bactérias Nitrosomonas e posteriormente a nitrato, pela ação de Nitrobacter (VINATEA 2004). No tratamento controle este processo não ocorreu. A concentração de nitrito cai a zero e permaneceu assim até o final, provavelmente, pela falta da ação das bactérias do primeiro grupo 
uma vez que, segundo Ferreira (2000), este processo deve ocorrer em condições apropriadas, caso contrário, os próprios produtos do metabolismo bacteriano podem causar toxidez ao meio deixando-o nocivo para as bactérias. Em contrapartida, neste mesmo tratamento foram verificados os maiores níveis de amônia (Figura 3).

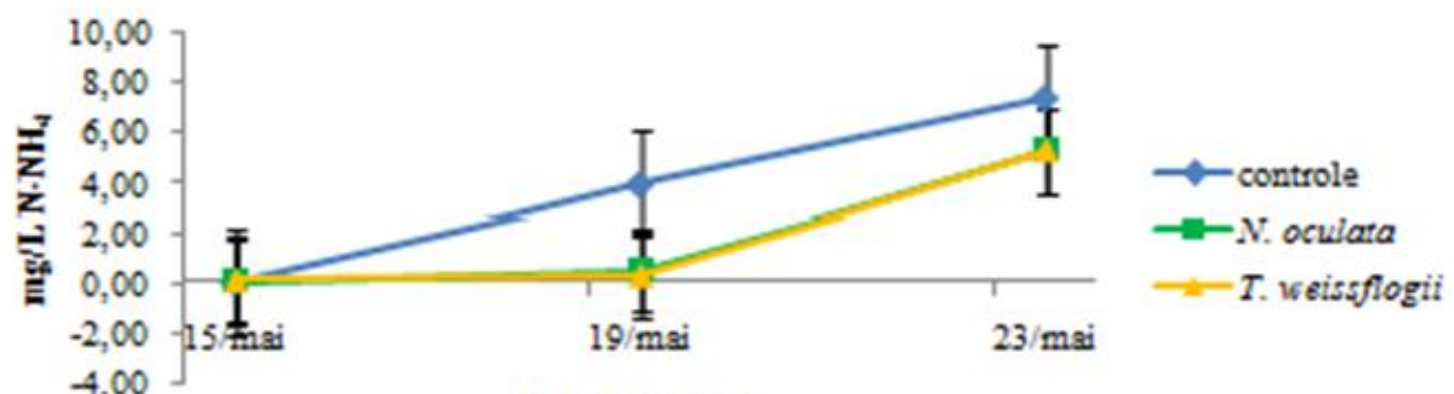

Dias de cultivo

A

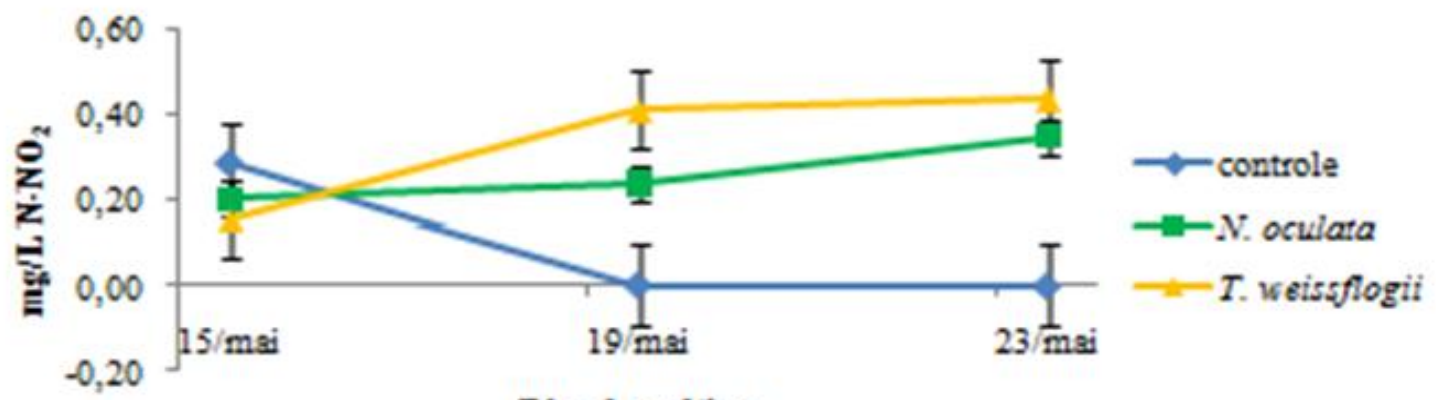

Dias de cultivo
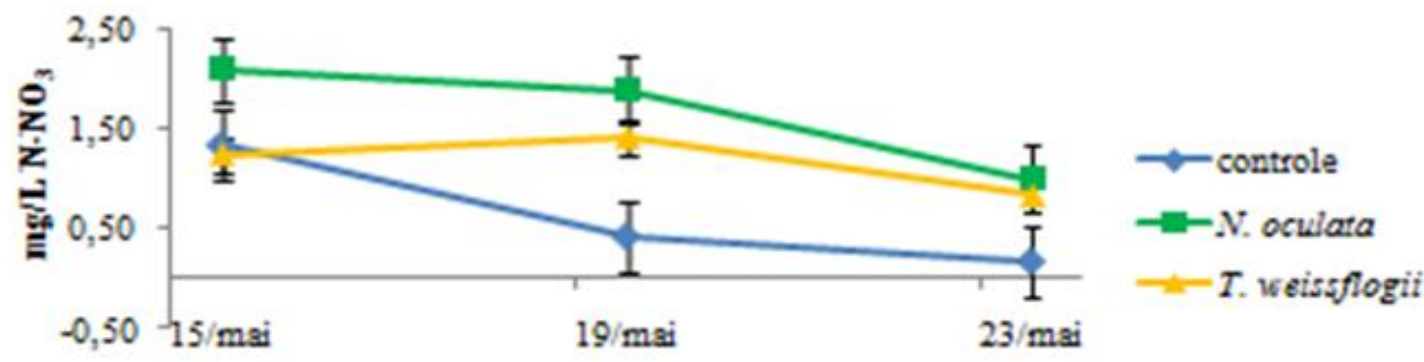

Dias de cultivo

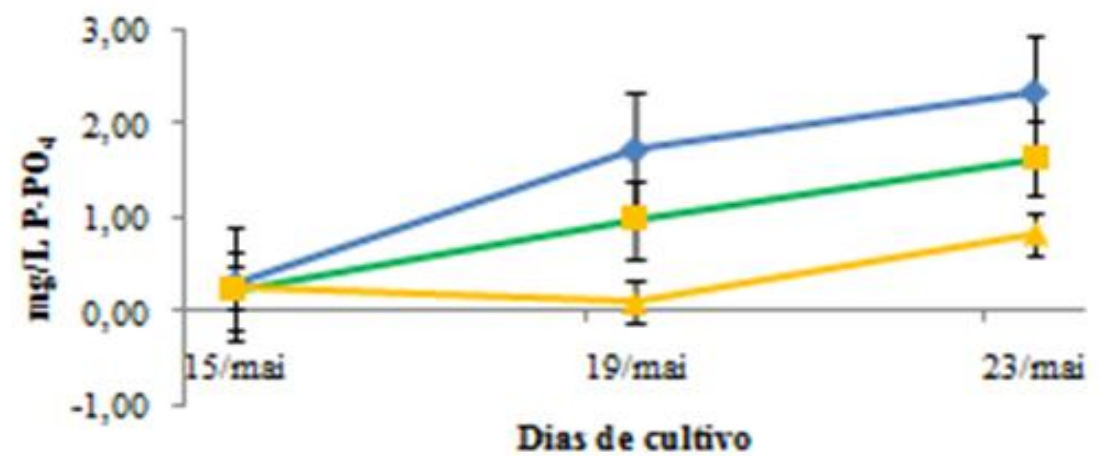

C

FIGURA 3 - Comportamento das variáveis de qualidade de água: amônia (A), nitrito (B), nitrato (C) e fosfato (D), durante o cultivo de póslarvas de $L$. vannamei em berçários sem renovação de água. 
Assim como o nitrito, a concentração de nitrato também se manteve dentro da faixa de tolerância do L. vannamei (SLA, 2009), porém, acima do descrito por Boyd (1998). Vinatea (2004) ressalta que a toxidez de nitrato parece não ser um problema para os animais aquáticos. Em todos os tratamentos foi observada uma redução da concentração de nitrato ao longo do cultivo. Este fato pode ser explicado pelo fato desta substância ser utilizada pelas bactérias, (MADIGAN 2004), e também pelas microalgas para promover o seu crescimento.

As concentrações de fosfato estiveram acima dos níveis citados por Vinatea (2004) e SLA (2009), que reportam concentrações desejadas de fósforo total menor que $0,3 \mathrm{mgL}^{-1}$ e de ortofosfato menor que $0,2 \mathrm{mgL}^{-1}$ respectivamente. Além do estímulo ao crescimento do fitoplâncton, este nutriente também é utilizado por bactérias e o seu acúmulo pode gerar condições propícias ao desenvolvimento de bactérias patogênicas (MOURIÑO et al. 2008; MADIGAN et al. 2004), podendo causar redução da sobrevivência.

A decomposição da ração associada aos produtos resultantes do metabolismo das pós-larvas contribuíram para aumentar os níveis de fosfato no tratamento sem microalgas durante este estudo, diferentemente daqueles onde a presença destas contribuiu para manter as concentrações deste nutriente em níveis menos elevados. No tratamento com a microalga $T$. weissflogii, foi possível observar que o nível de fosfato durante este estudo esteve bem próximo da faixa ideal, diminuindo assim 0 impacto deste nutriente no ambiente de cultivo e no ambiente circundante, quando da liberação da água por ocasião da despesca das pós-larvas.

Alguns fatores podem afetar o desempenho zootécnico dos animais. Qualidade e quantidade de alimento, densidade populacional, baixa qualidade da água e acúmulo de substâncias indesejáveis (ARNOLD et al. 2006) podem aumentar os níveis de stress e comprometer $o$ desenvolvimento dos camarões.

A sobrevivência obtida nos tratamentos foi elevada e esteve dentro da faixa (89-93\%) observada anteriormente por Moss \& Moss (2004) para o L. vannamei no tratamento com a microalga $N$. oculata $(90,4 \%)$ e um pouco acima no tratamento com $T$. weissflogii (95,5\%). Mesmo o menor índice de sobrevivência obtido no tratamento controle $(87 \%)$, sem microalgas, estando abaixo do estabelecido por estes autores, ficou acima dos limites descritos por Stern \& Letellier (1992) em berçários, que foi de 70 $80 \%$ (Figura 4).

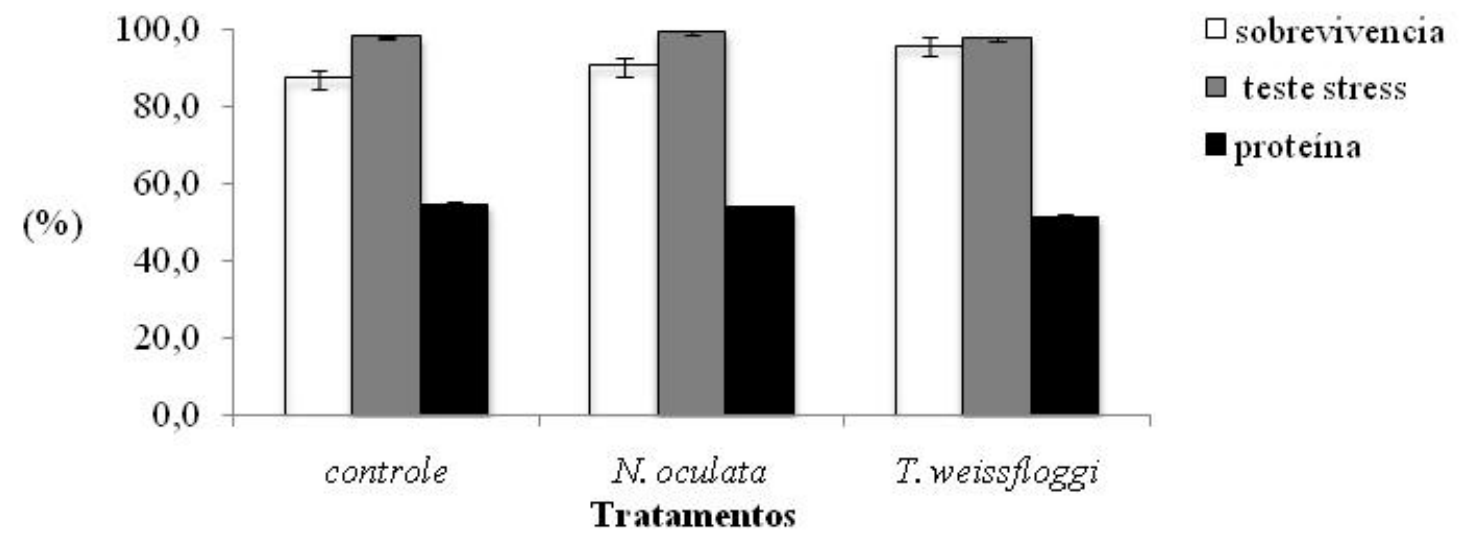

FIGURA 4 - Percentual de sobrevivência, de resistência ao teste de stress e níveis de proteína bruta total (média \pm desvio padrão), alcançados durante o cultivo em berçários intensivos de $L$. vannamei sem renovação de água.

Os altos níveis de proteína $(40 \%$ a $55 \%)$ presentes nos diferentes tipos de rações comerciais ofertados contribuíram para o desenvolvimento dos camarões. Segundo Cuzon et al. (2004), os níveis de proteína exigidos variam de acordo com a fase da vida, sendo que, para as pós-larvas, estes níveis compreendem de $30 \%$ a $35 \%$. A disponibilidade e qualidade do alimento fizeram com que as pós-larvas apresentassem níveis altos de proteína bruta (entre $51,1 \%$ a $54,5 \%$ ), maiores que os $44,1 \%$ verificados no 
início deste estudo. A alta pontuação obtida na avaliação da qualidade larval e tolerância elevada no teste de stress (Figura 4), demonstrando que as póslarvas estavam sadias e aptas a suportar os processos de aclimatação, anteriores ao povoamento nos viveiros de engorda, com segurança, independente do tipo de microalga utilizado ou não, durante o cultivo.

Santos et al. (2007), obtiveram os melhores resultados de crescimento em peso e comprimento $(0,560 \pm 0,096 \mathrm{~g}$ e $62,1 \pm 0,9 \mathrm{~mm}$ respectivamente) em pós-larvas de $I$. vannamei, alimentadas somente com ração comercial. Diferente destes autores, este estudo mostrou diferenças significativas no comprimento e no peso das pós-larvas cultivadas na presença das microalgas, sobretudo no tratamento com a microalga T. weissflogii (Tabela 5), com um aumento de 130,9\% sobre o peso seco inicial (Figura 5).

TABELA 5 - Valores médios e desvio padrão dos índices zootécnicos verificados para as pós-larvas de $L$. vannamei cultivadas em berçários intensivos, com as microalgas $N$. oculata e $T$. weissflogii, sem renovação de água.

\begin{tabular}{|c|c|c|c|}
\hline \multirow{2}{*}{ Variáveis } & \multicolumn{3}{|c|}{ Tratamentos } \\
\hline & Controle & N. oculata & T. weissflogii \\
\hline Sobrevivência (\%) * & $87,04( \pm 14,22)^{3}$ & $90,39( \pm 6,44)^{3}$ & $95,49( \pm 5,65)^{3}$ \\
\hline Proteina bruta $(\mathrm{g} \%)^{*}$ & $0,83( \pm 0,02)^{\mathrm{a}}$ & $0,82( \pm 0,02)^{a}$ & $0,80( \pm 0,04)^{\mathrm{a}}$ \\
\hline Qualidade larval (0-10) & $9,08( \pm 0,34)^{3}$ & $9,58( \pm 0,16)^{a}$ & $9,16( \pm 0,30)^{a}$ \\
\hline Teste Stress $(\%)^{*}$ & $97,89( \pm 2,55)^{3}$ & $99,07( \pm 0,74)^{3}$ & $97,66( \pm 2,84)^{\mathrm{a}}$ \\
\hline Peso seco médio final (mg/PL) & $0,526( \pm 0,030)^{b}$ & $0,546( \pm 0,034)^{b}$ & $0,981( \pm 0,090)^{\mathrm{a}}$ \\
\hline Ganho de peso (mg) & $0,101( \pm 0,031)^{b}$ & $0,122( \pm 0,034)^{b}$ & $0,556( \pm 0,090)^{3}$ \\
\hline Biomassa total prod. (mg) & $1327( \pm 383,9)^{b}$ & $1568( \pm 325)^{b}$ & $7887( \pm 1436)^{\mathrm{a}}$ \\
\hline Tx especifica crescimento $\left(\% \mathrm{dia}^{-1}\right)$ & $2,37( \pm 0,65)^{b}$ & $2,79( \pm 0,60)^{b}$ & $9,27( \pm 0,99)^{3}$ \\
\hline Crescimento (mm) & $8,24( \pm 0,21)^{b}$ & $9,11( \pm 0,17)^{\mathrm{a}}$ & $9,54( \pm 0,37)^{\mathrm{a}}$ \\
\hline CV (desv. pad/média) (\%) & $9,57( \pm 2,13)$ & $10,06( \pm 0,43)$ & $10,32( \pm 1,05)$ \\
\hline
\end{tabular}

* dados transformados (Arco seno ${ }^{2} \sqrt{ } \mathrm{x}$ ) anteriormente a análise.

Letras sobrescritas diferentes indicam diferença estatística significativa, TUKEY $(p<0,05)$.

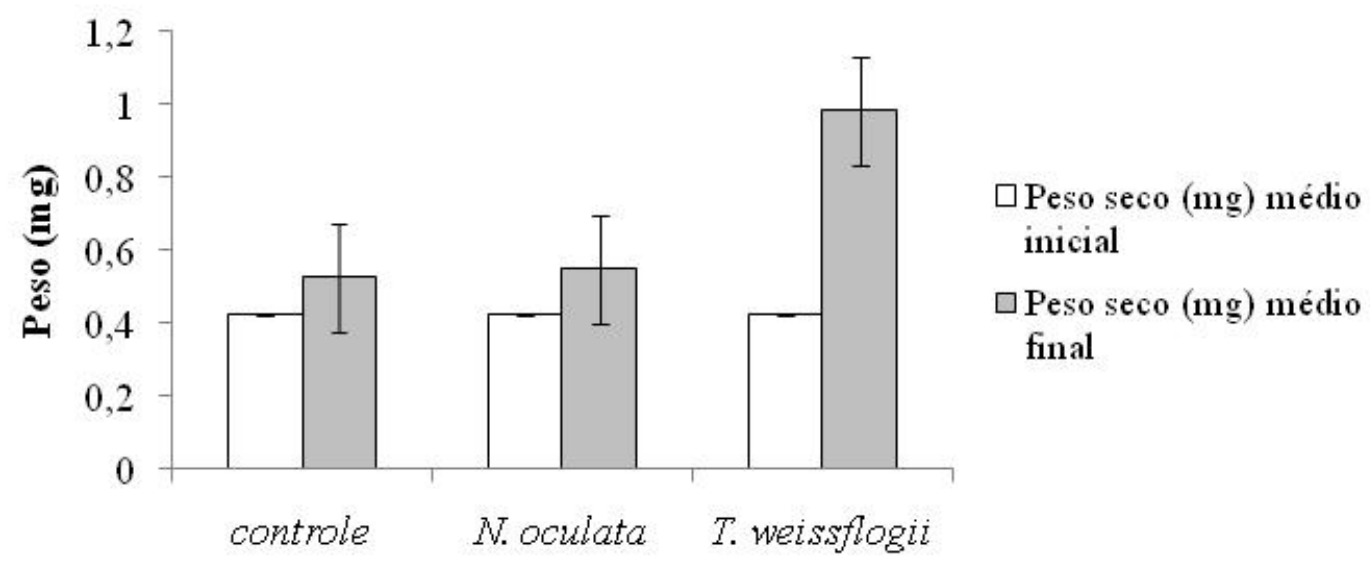

Tratam entos

FIGURA 5 - Peso seco final (médio) das pós-larvas de L. vannamei cultivadas em berçários intensivos com as microalgas $N$. oculata e $T$. weissflogii, sem renovação de água. 
Silva \& Mendes (2006) observaram que o uso de artemia na dieta de pós-larvas aumentou em $28,07 \%$ o peso, em relação aquelas que receberam apenas ração comercial. Piña et al. (2005) obteve os melhores resultados de sobrevivência, crescimento em peso e comprimento quando a dieta a base de náuplios de artemia foi suplementada com a microalga $C$. muelleri, para larvas do camarão marinho $L$. vannamei. Este resultado está relacionado à disponibilidade dos ácidos graxos poliinsaturados presentes nas microalgas. Embora a espécie $N$. oculata apresente um bom potencial para a produção destes compostos energéticos, como é o caso do EPA e de estudos como os de Hu \& Gao (2006), objetivando aumentar a produção deste composto sob diferentes condições, as diatomáceas ainda são as microalgas mais utilizadas como alimento natural e, segundo Derner (2006), a espécie T. weissflogii possui um valor nutricional melhor do que a $C$. muelleri, devido a sua composição bioquímica (maiores valores de EPA e DHA).

Ainda que o comprimento das pós-larvas não tenha apresentado diferença significativa entre os tratamentos com as microalgas, o peso seco médio final no tratamento com a $T$. weissflogii foi significativamente maior, reflexo da maior taxa

\section{CONCLUSÕES}

Este estudo demonstrou que o tipo de alimento disponibilizado às larvas permite a manutenção dos níveis de qualidade de água em condições aceitáveis, sendo possível cultivar pós-larvas de Litopenaeus vannamei em densidades elevadas sem renovação de água e reposição de microalgas.

A utilização da Thalassiosira weissflogii durante o cultivo pode levar a concentrações menores de amônia e fósforo, através da própria assimilação, diminuindo o efeito dos efluentes no meio ambiente, além do que, neste estudo, favoreceu o melhor desempenho das pós-larvas do camarão marinho Litopenaeus vannamei.

De acordo com este estudo é possível a utilização da Nannochloropsis oculata durante o cultivo em berçários sem prejudicar o desempenho dos animais. específica de crescimento verificada $\left(9,27 \% \mathrm{dia}^{-1}\right)$. Isto está relacionado a presença dos carboidratos, lipídeos e proteínas presentes nas microalgas (POISSON \& ERGAN, 2001). Silva (2003) cita que as proteínas e vitaminas são utilizadas na formação de tecidos, os carboidratos e lipídeos têm funções energéticas, enquanto que os minerais e vitaminas solúveis agem como componentes funcionais de coenzimas.

Outro fator que pode ter contribuído para o alcance destes índices de crescimento em peso foi à presença maior de protozoários móveis, grumos (material floculado) contendo células de microalgas, bactérias e material orgânico, causando diminuição da transparência da água e aumentando a quantidade de material sedimentável, principalmente no tratamento com a microalga $T$. weissflogii, uma vez que este estudo foi conduzido sem renovação de água.

Esta afirmação é corroborada pelos estudos de Burford et al. (2004) que afirma serem as partículas floculadas, uma potencial fonte de alimento para o camarão e de Zhou et al. (2009), que avaliaram o papel e as funções dos microorganismos benéficos na aqüicultura sustentável, citando dentre outras, estímulo ao crescimento e melhorando o fator de conversão alimentar dos alimentos.

\section{AGRADECIMENTOS}

A toda a equipe do Laboratório de Camarões Marinhos (LCMUFSC) pela disponibilização da infra-estrutura necessária e ajuda na execução deste estudo.

\section{REFERÊNCIAS}

APHA (American Public Health Association). 1995. Standard methods for examination of water and wastewater. 14. ed. Washington, DC. 1193p.

ARNOLD, SJ, MJ SELLARS, PJ CROCOS \& GJ COMAN. 2006. Intensive production of juvenile tiger Penaeus monodon. An evaluation of stocking density and artificial substrates. Aquaculture, 261: 890-896.

AOAC (Association of Official Analytical Chemists). 2005. Official Methods of Analysis of AOAC International. 18th Edition, Arlington, USA.

BARAJAS, FJM, RS VILLEGAS, GP CLARK \& BL MORENO. 2006. Litopenaeus vannamei (Boone) post-larval survival 
related to age, temperature, $\mathrm{pH}$ and ammonium concentration. Aquaculture Research, 37: 492-499.

BARBIERI, R \& A OSTRENSKY. 2002. Camarões Marinhos Engorda. Aprenda Fácil Ed. Viçosa, vol. 2, 370 p.

BOYD. C. E. 1998. Pond and water aeration sistems. Aquaculture Engineering, 18: 9-40.

BURFORD, MA, PJ THOMPSON, RP McINTOSH, RH BAUMAN \& DC PEARSON. 2004. The contribution of flocculated material to shrimp (Litopenaeus vannamei) nutrition in a highintensity, zero-exchange system. Aquaculture, 232: 525-537.

CUZON, G, A LAWRENCE, G GAXIOLA, C ROSAS \& J GUILLAUME. 2004. Nutrition of Litopenaeus vannamei reared in tanks or in ponds. Aquaculture, 235:513-531.

DANTAS, D, JP NETO, A OLIVEIRA, S PEIXOTO \& R SOARES. 2007. Crescimento de Thalassiosira fluviatilis, Chaetoceros muelleri e Navícula sp. em diferentes protocolos de fertilização. In: IV - FENACAM - Feira Nacional do Camarão, Natal. FENACAM - Feira Nacional do Camarão. Apresentação de Trabalhos Técnicos. Natal - RN, 2007. p. 14-15.

DERNER, R. B. 2006. Efeito de fontes de carbono no crescimento e na composição bioquímica das microalgas Chaetoceros muelleri e Thalassiosira fluviatilis, com ênfase no teor de ácidos graxos poliinsaturados. 2006. Tese/Doutorado, Departamento de Ciências e Tecnologia de Alimentos, Universidade Federal de Santa Catarina, Florianópolis. $158 \mathrm{p}$.

EBELING, J.M. MB TIMMONS and JJ BISOGNI. 2006. Engineering analysis of the stoichiometry of photoautotrophic, autotrophic, and heterotrophic removal of ammonia-nitrogen in aquaculture systems. Aquaculture, 257, issues 1-4: 346358.

FERREIRA, E. Cinética química e fundamentos dos processos de nitrificação e desnitrificação biológica. In: CONGRESSO INTERAMERICANO DE ENGENHARIA SANITÁRIA E AMBIENTAL, 27. 2000, Porto Alegre. Anais... Rio de Janeiro: ABES, 2000. 1 CD-ROM.

$\mathrm{HU}, \mathrm{H}$, \& K GAO. 2006. Response of growth and fatty acid compositions of Nannochloropsis sp. to environmental factors under elevated $\mathrm{CO}_{2}$ concentration. Biotechnal Lett, 28: 987992.

IGARASHI, MA, RK KOBAYASHI, JM PENAFORTE \& JR de O CÉSAR. 1996. Cultivo em massa de pós-larvas de Penaeus japonicus em tanques com microalgas Nannochloropsis sp. Ciência Agronômica, 27, $n^{\circ} 1 / 2$ : 34-38.

KAUTSKY, P, M RÖNBÄCK, M TEDENGREN e TROELL. 2000. Ecosystem perspectives on management of disease in shrimp pond farming. Aquaculture, 191: 145-161.

KNOLL, RC, DS MAGGIONI, R SCHVEITZER \& WQ SEIFFERT. 2007. Desenvolvimento de metodologia para a avaliação de qualidade de pós-larvas de camarões marinhos da espécie Litopenaues vannamei. In: XII COLACMAR - Florianópolis. Anais: Congresso Latino-Americano de Ciências do Mar, 15 a 19 de abril de 2007.

MADIGAN, MT, JM MARTINKO \& J PARKER. 2004. Microbiologia de Brock. $10^{\text {th }}$ ed., Upper Saddle River: Prentice Hall, 610p.

MOURIÑO, JLP, C BUGLIONE, FN VIEIRA, C RAMIREZ, FS PEDROTTI, F BELETTINI, WQ SEIFFERT \& E BELTRAME. 2008. Avaliação bacteriológica aplicado à produção de pós- larvas de Penaeus vannamei. Atlântica, 30: 9-16.

MOSS, K \& S MOSS. 2004. Effects of artificial substrate and stocking density on the nursery production of pacific white shirimp Litopenaues vannamei. Journal of the WAS, 35(4): 536-542.

PEREIRA, RC \& A SOARES-GOMES. 2002. Biologia marinha. Interciência, 2를 ${ }^{\mathrm{a}}$. Rio de Janeiro, p.195-227.

PIÑA, P, M NIEVES, L RAMOS-BRITO, CO CHAVIRA-ORTEGA \& D VOLTOLINA. 2005. Survival, growth and feeding efficiency of Litopenaeus vannamei protozoea larvae fed different rations of the diatom Chaetoceros muelleri. Aquaculture, 249: 431-437.

POISSON, L \& F ERGAN. 2001. Docosahexaenoic acid ethyl esters from Isochrysis galbana. Journal of Biotechnology, 91: 75-81.

SANTOS, CH dos A dos, JA LOURENÇO, HJ dos A COSTA \& MA IGARASHI. 2007. Avaliação do ganho de peso de póslarvas do camarão marinho Litopenaeus vannamei (Boone, 1931), alimentados com peixes da fauna acompanhante do camarão marinho. Ciência Animal Brasileira, v. 8, n. 1, p.7-15, jan./mar.

SAMOCHA, TM \& AL LAWRENCE. 1992. Shirimp nursery systems and management. In: J Wyben, editor. Procedings of Special Sessions on Shirimp Farming. World Aquaculture society, Baton Rouge, Lousiana, EUA. Pg: 87-105.

SILVA, AP. 2003. Viabilidade do uso de Artemia franciscana (Kellogg, 1906) de Grossos-RN, Brasil, no cultivo de Litopenaeus vannamei (Boone, 1931) em tanques-berçário. Dissertação (Mestrado em Recursos Pesqueiros e Aqüicultura), Departamento de Pesca, Universidade Federal Rural de Pernambuco, Recife. $78 \mathrm{p}$.

SILVA, AP \& PP MENDES. 2006. Utilização da artêmia nacional como dieta para pós-larvas do Litopenaeus vannamei (Boone, 1931) na fase berçário. Acta Scientiarum. Animal Sciences, 28, 03: 345-351.

SLA (Sociedad Latinoamericana de Acuacultura). 2009. La evaluacion de impacto ambiental como instrumento fundamental de dearrollo de La acuacultura em México. Elaborado y revisado por Blgo. Jorge Chávez. Indústra acuícola 5(4): 6-15.

STERN, S \& E LETELLIER. 1992. Nursery systems and management in shirimp farming in Latin America. In: J. Wyban, editor. Proceedings of the special session on shirimp farming - WAS, Baton Rouge, Loisiana, EUA

SUKENIK, A. 1999. Eicosapentaenoic acid by the marine eustigmatophyte Nannochloropsis. In: Chemicals from microalgae. Taylor \& Francis. Cohen Z (ed), London, p: 41-56, $419 \mathrm{p}$.

THOMPSON, FL, PC ABREU \& W WASIELESKY. 2002. Importance of biofilm for water quality and nourishment in intensive shrimp culture. Aquaculture, 203: 263-278.

VIEIRA, FN, FS PEDROTTI, C BUGLIONE, JLP MORINÕ, E BELTRAME, ML MARTINS, C RAMIREZ \& LA VINATEA, LA. 2007. Lactic-acid bactéria increase the survival of marine shirimp, Litopenaeus vannamei, after infection with Vibrio harveyi. Brazilian Journal of Oceanography, 55(4): 251-255.

VINATEA, LA. 2004. Princípios químicos de qualidade da água em aqüicultura: uma revisão para peixes e camarões. $2^{\mathrm{a}}$ ed. Revisada e Ampliada. Florianópolis: Editora da UFSC, 231 p. 
BELETTINI, F.; DERNER, R.B.; VINATEA, L.A.

ZHOU, Q, K LI, X JUN \& L BO. 2009. Role and functions of beneficial microorganisms in sustainable aquaculture.
Bioresource Technology, 100: 3780-3786.

Submetido - 02/06/2010

Aceito - 05/05/11 